\title{
Mecanismos negociados de resolución de conflictos penales en Chile y Alemania: Una aproximación pragmática
}

\author{
Negotiated Mechanisms for the Resolution of \\ Criminal Disputes in Chile and Germany: A \\ Pragmatic Approach \\ Carlos Correa Robles*
}

Recepción y evaluación de propuesta: 30/8/18

Aceptación con revisiones: 10/2/19

Recepción y aceptación final: 8/3/19

\begin{abstract}
Resumen: El trabajo analiza algunas tensiones generadas a partir de la implementación de mecanismos negociados de resolución de conflictos penales en los sistemas procesales alemán y chileno, a la luz de la teoría de las traducciones legales, de Máximo Langer. Se busca describir el impacto que dichos mecanismos generan sobre la estructura procesal en la que se encuentran insertos, explicando las causas que fomentan su utilización y proponiendo finalmente estrategias que permitan racionalizar su uso.

Palabras clave: justicia penal negociada, acuerdos, conformidad del imputado.
\end{abstract}

\begin{abstract}
This work analyzes, in light of Máximo Langer's theory of Legal Translations, some of the tensions generated by the implementation in German and Chilean procedural systems of negotiated mechanisms for the resolution of criminal disputes. The paper purports to describe the impact
\end{abstract}

Dr. Iur. y LL.M, Freie Universität Berlin. Profesor Derecho Procesal, Universidad Adolfo Ibáñez, Santiago, Chile. Correo electrónico: c.correa@uai.cl 
of such mechanisms in the procedural structures where they are inserted and to explain the main reasons for their use. Finally, some strategies for improving their use are proposed.

Keywords: negotiated criminal justice, plea agreements, agreement by the defendant.

\section{Introducción}

En un mundo globalizado, el intercambio de información y conocimiento entre diversos actores sociales, constituye una realidad. El derecho no escapa a dicho fenómeno. Las pretéritas fronteras que, por ejemplo, distanciaban aquellos ordenamientos jurídicos regidos por el common law de aquellos de tradición continental, se han vuelto cada vez más tenues ${ }^{1}$.

Dicho fenómeno ha permeado de manera especialmente intensa, como demuestra el trabajo de Máximo Langer que aquí se comenta ${ }^{2}$, al proceso penal. El viejo sistema inquisitivo - predominante en Europa Continental durante siglos, hasta su progresivo desmantelamiento a partir de mediados del siglo XIX, ${ }^{3}$ y en algunas regiones de América Latina vigente (en su versión más impúdica) hasta fines del siglo $\mathrm{XX}^{4}-$ caracterizado por la oficialidad de la instrucción, el principio de legalidad irrenunciable y la búsqueda de la verdad material como finalidad última del proceso, ha transitado hacia caminos que antes parecían vedados.

1 Un panorama general referido especialmente al derecho probatorio se encuentra en: Damaska, M., El derecho probatorio a la deriva, Madrid y otros, Marcial Pons, 2015, passim.

2 Langer M., "De los trasplantes legales a las traducciones legales: la globalización del plea bargaining y la tesis de la 'americanización' en el proceso penal”, en este volumen de Discusiones.

3 El comienzo del fin del sistema inquisitivo "puro" puede situarse en la creación e implementación del Ministerio Público como órgano persecutor autónomo de la judicatura a comienzos del siglo XIX. Véase Roxin, C., "La posición jurídica de la fiscalía ayer y hoy", en Guerrero, Ó (traductor), Pasado presente y futuro del Derecho Procesal Penal, Buenos Aires y Santa Fe, Rubinzal - Culzoni Editores, 2007, pp. 9-38, p. 9 y ss.

4 Paradigmático es el caso de Chile, país donde hasta el año 2000 rigió un modelo inquisitivo puro consagrado en el Código de Procedimiento Penal de 1906 caracterizado por un Juez del Crimen, encargado de investigar, acusar y juzgar. 
Las sucesivas reformas introducidas en las últimas décadas a los sistemas herederos de la tradición inquisitiva han permitido flexibilizar ciertos dogmas de dicho modelo. Principios, estructuras y finalidades del proceso penal que hace menos de un siglo se consideraban barreras infranqueables del mismo, hoy se erigen como elementos indispensables de cualquier sistema de persecución racional. En este sentido, la renuncia al dogma de la averiguación de la verdad "a cualquier precio" a favor de la consagración de derechos y garantías del imputado, el establecimiento del principio de oportunidad, la instauración de oralidad en los procedimientos penales, la inmediación en la recepción de prueba, e incluso el reconocimiento de ciertas facultades de ejercicio de la acción penal a cargo de la víctima, constituyen elementos que hoy en día (en mayor o menor medida) resultan comunes a prácticamente todos los sistemas procesales penales europeos y latinoamericanos.

Especial relevancia tiene a este respecto, como lo demuestra el texto de Langer, la progresiva incorporación -formal e informal- de respuestas negociadas al conflicto jurídico-penal, que han permitido ampliar los estrechos márgenes del proceso penal decimonónico y - como se verá- esquivar algunas deficiencias propias del procedimiento ordinario.

Si bien dichos mecanismos, más allá de su contenido específico (que puede diferir caso a caso), buscan fomentar soluciones rápidas, eficientes y en principio satisfactorias para los actores involucrados, no resultan exentos de polémicas.

Las críticas formuladas a este respecto (muchas de las cuales se analizan en este artículo), se han dirigido históricamente tanto respecto de aquellos ordenamientos que han incorporado en las últimas décadas soluciones negociadas, como también para aquellos modelos en los cuales la conformidad del acusado ha constituido, prácticamente desde el origen mismo del sistema, un mecanismo esencial del proceso penal, como lo es, paradigmáticamente, el sistema estadounidense.

En su clásico artículo "Torture and Plea Bargaining"5, advertía Langbein - idesde el derecho estadounidense! - acerca de los peligros que

5 Langbein, J., “Tortura y plea bargaining”, en Maier, J. y Bovino, A. (coord.), El procedimiento abreviado, Buenos Aires, Editores del Puerto, 2001, pp. 3-29. 
el plea bargaining encierra. Contrastando la ya entonces asentada práctica de las negociaciones entre acusador y acusado, con el ejercicio de la tortura como medio idóneo para obtener una confesión en el derecho medieval, sostenía el autor que el sistema vigente en los Estados Unidos hace terriblemente costoso para un acusado reclamar el ejercicio de su derecho a la garantía constitucional del juicio previo. La amenaza que pende sobre el imputado, como espada de Damocles, de imponerle una sanción sustancialmente más elevada si decide ejercer su derecho a defensa y posteriormente es declarado culpable, puede convertir a una institución concebida bajo la lógica del beneficio mutuo, finalmente, en un instrumento coercitivo ${ }^{6}$.

El presente trabajo busca analizar algunos aspectos centrales del texto de Máximo Langer, a partir de las tensiones y contradicciones que ha generado la introducción de salidas negociadas al conflicto penal en los sistemas chileno y alemán, tributarios de culturas jurídicas inicialmente hostiles a tales prácticas. En este sentido, se busca finalmente confrontar la validez de una de las tesis fundamentales del trabajo de Langer ${ }^{7}$, consistente en entender la transferencia de instituciones legales de un sistema a otro, como traducciones de un sistema de sentido hacia el otro.

Para tales efectos se analizará el modo en el cual se contraponen los beneficios que generan dichas prácticas negociadas, con los problemas que han impedido su plena y pacífica inserción en los sistemas alemán y chileno, explicando las posibles causas de ello y proponiendo finalmente algunas soluciones.

6 Ibidem, p. 15.

7 Langer M., op cit., sección 1. 


\section{El plea bargaining estadounidense: paradigma de los mecanismos consensuados de resolución de conflictos penales}

Los acuerdos en torno a la declaración de culpabilidad del imputado en el sistema estadounidense a cambio de ciertas concesiones, tuvieron su origen $^{8}$ como una práctica solapada, llevada a cabo a comienzos del siglo XIX entre fiscales e imputados a espaldas de los tribunales. Décadas más tarde, la confesión negociada del acusado comenzó a incentivarse en un gran porcentaje de los casos, convirtiéndose ya a fines del siglo XIX y comienzos del XX en un mecanismo estandarizado de resolución de conflictos penales, debido al alto costo que significaba el juicio y el tiempo que éste tardaba en llevarse a cabo.

Fue sin embargo varias décadas más tarde, en Brady v. United States ${ }^{9}$, fallo representativo de este cambio institucional dirigido a la aceptación jurídica de aquellas prácticas, cuando se dotó explícitamente de legitimación a este tipo de acuerdos. Al respecto, sostuvo entonces la Corte Suprema estadounidense: “(...) No podemos sostener que es inconstitucional que el Estado otorgue una concesión al acusado que a cambio le proporcionará un beneficio sustancial y que demuestra por su declaración que está preparado y dispuesto para admitir su delito y someterse al sistema correccional (...)"

Igualmente, la comentada sentencia exigió ciertos requisitos para dotar de validez y eficacia de las negociaciones, a saber, la inexistencia de presiones, amenazas o falsas promesas al acusado, o sobornos al fiscal. Al respecto, prosigue la Corte señalando: "Una declaración de culpabilidad prestada por el acusado plenamente consciente de todas las consecuencias, enterado de sus efectivos compromisos asumidos en su confrontación con el juez, con el acusador o con el mismo defensor, debe ser considerada válida y eficaz salvo que hay a sido arrancada con amenazas (o con promesas de hacer

8 Sobre la evolución histórica del plea bargaining en los Estados Unidos, véase Correa C. y Reyes, M., El procedimiento abreviado y la justicia criminal negociada - Derecho chileno y comparado--, Santiago, Ed. Jurídica de Chile, 2012, p. 29 y ss.

9 Brady v. United States 397 U.S. 742, 752-753, 90 S.Ct. 1463, 25 F.2d 747 (1970). Las traducciones son de mi autoría. 
cesar hostigamientos injustos), con falsas manifestaciones (incluso promesas no mantenidas o que no hubieren podido mantenerse), o bien con promesas que por su naturaleza son ilegítimas (por ejemplo el pago de un precio por soborno) (...)."

Transcurridos casi cincuenta años desde el pronunciamiento de la sentencia citada, en los Estados Unidos el plea bargaining parece ser, sin lugar a dudas, el procedimiento ordinario de facto, pasando el juicio por jurados a ser una especie de elefante blanco, que es mirado con temor y recelo por parte de acusados y defensores, atendida la elevada probabilidad de obtener una decisión judicial menos favorable que la susceptible de ser acordada.

La razón subyacente que ha inspirado a la introducción de mecanismos de justicia penal consensuada en los Estados Unidos fue asumida explícitamente el año 1971 por la Corte Suprema en Santobello v. New York ${ }^{10}$, dejando al desnudo la imperiosa necesidad, esta vez por razones utilitaristas, de acceder a salidas alternativas al juicio por jurados: “(...) la disposición de los cargos (...) no solo es una parte esencial del proceso, sino que representa, además, un mecanismo altamente deseable por múltiples razones. Conduce a una rápida y definitiva resolución de la mayoría de los procesos penales; evita muchos de los efectos corrosivos debido a la forzosa ociosidad durante la prisión preventiva de aquellos a quienes les ha sido denegada la libertad en espera de un juicio; protege a la sociedad de aquellos acusados inclinados a persistir en su conducta criminal incluso durante la libertad provisional; $y$, abreviando los plazos que discurren entre la acusación y la sentencia, incrementa las perspectivas de rehabilitación del culpable una vez que, pronunciada la condena, este venga sometido al tratamiento penitenciario."

La praxis ha demostrado que el plea bargaining resulta necesario para el buen funcionamiento de la administración de justicia estadounidense; todos se esfuerzan por promover y favorecer su realización; en los Estados Unidos, los acuerdos negociados son no solamente necesarios, sino incluso deseables. 


\section{Los Absprachen en el sistema alemán: desde la informa- lidad a su consagración legal ${ }^{11}$}

A partir de la fundación de la República Federal Alemana en 1949, el sistema jurídico de dicho país ha experimentado - tanto a nivel legislativo como jurisprudencial - innegables cambios. En materia procesal penal, los cimientos del modelo inquisitivo reformado instaurado originalmente en la Ordenanza Procesal Penal Imperial (RStPO) de 1877, caracterizado por el apego irrestricto a los principios de oficialidad, legalidad y de la averiguación de la verdad material como fin del proceso penal, han comenzado lentamente a resquebrajarse. La estructura monolítica característica de dicho sistema, que concebía una estricta unidad entre hecho e imputado, esbozado por Beling hace más de 100 años $^{12}$, ha dado paso a soluciones que se alejan de dicha premisa, privilegiándose hoy en día soluciones rápidas al conflicto jurídico-penal, en desmedro de la total averiguación de la verdad y del subsecuente castigo para el delincuente.

La introducción de las salidas negociadas en el derecho alemán corresponde, al igual que la introducción de la teoría de las llamadas "prohibiciones probatorias" (Beweisverbote) ${ }^{13}$, a un claro ejemplo de ello. La incorporación de ambas instituciones, originalmente extrañas al sistema, ha permitido que hoy en día se erijan como instrumentos esenciales del mismo.

${ }^{11}$ Si bien esta sección podría parecer redundante con el texto de Langer, resulta importante hacer referencia a la evolución histórica de los Absprachen en Alemania. Al respecto, cabe tener presente que la descripción de las salidas negociadas en el proceso penal alemán, referida en el artículo que aquí se comenta, describen un estadio previo de la regulación, el cual no considera la reforma legal introducida hace ya 10 años por medio de la cual éstos acuerdos fueron formalmente incorporados a la StPO.

12 "El contenido del proceso penal se encuentra determinado a partir de un único y específico hecho delictivo cometido por un imputado: ambos - hecho e imputado-constituyen una inquebrantable unidad”. Beling, E. y Bennecke, H., Lehrbuch des Deutschen Reichs-Strafprozessrecht, Breslau, Schletter'sche Buchhandlung, 1900, p. 204.

${ }^{13}$ Sobre la evolución histórica de las prohibiciones probatorias en el derecho alemán, véase Correa, C. "Más allá de la regla de exclusión: prohibiciones probatorias en el Derecho chileno - con especial referencia al Derecho alemán-”, Política Criminal, 13 (25), 2018, pág. 146 y ss. 
En lo que respecta a las soluciones consensuadas al conflicto penal, pese a constituir inicialmente un elemento propio de sistemas jurídicos tradicionalmente contrapuestos al alemán, el origen y evolución experimentado por los Absprachen se asimila en gran parte al ya descrito camino recorrido por el plea bargaining en el derecho estadounidense.

Desde la década de 1970 fiscales y defensores comenzaron, a espaldas de los tribunales, a introducir mecanismos de salida consensuada al conflicto penal. El objeto de dichos acuerdos correspondía a una disminución de la pena aplicable o bien, a la aplicación de una sanción más o menos determinada, a cambio de la entrega de una confesión total o parcial de parte del imputado ${ }^{14}$.

Tras años de oscuridad respecto a la legalidad, presupuestos de aplicación y requisitos de validez de dichos acuerdos, el primer pronunciamiento del Tribunal Federal Supremo (BGH) al respecto tuvo lugar recién en 1997, oportunidad en la cual — contra legem (!) — dicho tribunal ratificó la validez jurídica de los acuerdos, indicando sin embargo (y de un modo similar a Brady v. United States) detalladas reglas para su aplicación válida ${ }^{15}$. Las razones esgrimidas por el $\mathrm{BGH}$ en dicha oportunidad, para autorizar e incluso fomentar los acuerdos, se pueden resumir en la necesidad de lograr una mayor eficiencia en la persecución penal, obtener una ganancia en términos de economía procesal, favorecer el derecho a ser juzgado dentro de un plazo razonable y, asimismo, generar mecanismos de protección a la víctima ${ }^{16}$. Como vimos, un catálogo de virtudes similar al esgrimido por la Corte Suprema estadounidense en Santobello v. New York.

En los años venideros, y hasta su reconocimiento legal en el año 2009, los lineamientos jurisprudenciales para la aplicación de estos acuerdos se mostraron siempre insuficientes ante la incesante práctica de tribunales

\footnotetext{
${ }^{14}$ Beulke W., Strafprozessrecht, 11. Ed., Heildelberg y otros, C.F. Müller, 2010, p. 247.

15 Sobre la historia de los Absprachen en el derecho alemán, véase Varios Autores, SK-StPO: Systematischer Kommentar zur Strafprozessordnung. Mit GVG und EMRK, Editado por: Wolter, Tomos III: $\$ \$ 137$ - 197 y V: $\$ \$ 246 a-295$ StPO, 5. Ed., Köln, Heymanns, 2016: SK-StPO-Velten Vor 257b-257c ff, Rn. 1 y ss. 
Mecanismos negociados de resolución de conflictos penales en Chile y Alemania

inferiores que, sin trepidar, fomentaban y aplicaban — a veces indiscriminada y desproporcionadamente ${ }^{17}$ - dichos acuerdos.

En efecto, el carácter no vinculante que durante mucho tiempo caracterizó a estas negociaciones informales y desreguladas, posibilitó que en algunas oportunidades el ente persecutor desconociera ex post su contenido, lesionando con ello el principio del debido proceso. Desde luego, la vulneración - muchas veces impune- a la legítima confianza depositada por el imputado y su defensor en un acuerdo frustrado no debía ser tolerada. La solución a esta y otras prácticas abusivas vino - ya lo adelantamos- de la mano del legislador.

Siguiendo una práctica recurrente en el derecho alemán ${ }^{18}$, frente a una reiteración de sentencias pronunciadas en un mismo sentido por los tribunales superiores y a efectos de poner límite a ciertos abusos e incertidumbre reinante, el legislador decidió recoger y $\operatorname{codificar}^{19}$ los principales lineamientos jurisprudenciales expresados previamente por el BGH sobre esta materia, regulando en la StPO — nuevos $\$ \$ 257$ a), b) y c) - los acuerdos ${ }^{20}$.

El reconocimiento legal de estas salidas negociadas constituyó una respuesta por parte del legislador a una práctica jurisprudencial asentada y tolerada, que se remontaba — como se señaló- a varias décadas atrás ${ }^{21}$. Con dicha solución, al menos formalmente, el legislador alemán ha buscado

${ }^{17}$ Por ejemplo, una pena de 2 años se ofreció en una oportunidad, previa confesión, en un caso de evasión de impuestos, delito cuya pena no resulta inferior a los 6 años de privación de libertad. El LG München ofreció igualmente una pena de 2 años al presunto autor de 37 delitos de abuso sexual, a sabiendas que la pena a imponer sin dicho acuerdo no sería inferior a los 7 años. Véase Kempf, E., "Gesetzliche Regelung von Absprachen im Strafverfahren? Oder: Soll informelles formalisiert werden?", StV, 2009, pp. 269-276, p. 270.

18 Otro ejemplo de codificación de reglas creadas a nivel jurisprudencial se encuentra en el establecimiento de presunciones de causalidad y culpa en materia de responsabilidad contractual médica, contenidas en el nuevo $\$ 630$ h) BGB.

19 Reforma a la Ordenanza Procesal Penal (StPO) de 28.05.2009.

${ }^{20}$ De esta forma, la aseveración sostenida por Langer M, op. cit. sección 7, de acuerdo a la cual los traductores del plea bargaining alemán no tenían la autoridad para modificar formalmente otros aspectos del procedimiento penal mediante una reforma del Código Procesal Penal, ha sido desmentida por medio de esta reforma legal.

${ }^{21}$ Beulke, Strafprozessrecht, 11. Ed., 2010, p. 247. 
poner fin a las múltiples críticas formuladas por parte de la doctrina ${ }^{22}$, la cual reiterada e insistentemente, reclamó por años — ante la innegable realidadla necesidad de suprimir, o al menos regular a nivel legal dichas prácticas.

Los Absprachen constituyen hoy en día una práctica no sólo asentada, sino de masiva ocurrencia ante los tribunales alemanes. Si originalmente estos acuerdos se limitaban casi exclusivamente a casos de criminalidad económica, hoy en día trascienden a diversos delitos. De hecho, en el año 2011 cerca del $20 \%$ del total de casos penales tramitados ante tribunales inferiores (Amtsgericht y Landgericht), fueron resueltos utilizando esta vía ${ }^{23}$.

\section{Luces y sombras en torno a los acuerdos en el sistema alemán}

Como sostiene Volk, existen poderosas razones a favor de un acortamiento y conclusión anticipada del proceso penal por medio de soluciones consensuadas al conflicto penal. Ello se manifiesta sobre todo en casos en los cuales la cantidad de evidencia y el nivel de complejidad resultan tan elevados, que en la práctica se convierten en inmanejables. Un juicio oral de años de duración no sólo bloquea al tribunal encargado de su conocimiento, sino que resulta muchas veces un ejercicio en gran medida innecesario: la resolución que finalmente adoptará el órgano adjudicador no suele distar mucho de lo esperable por los intervinientes al comienzo del juicio ${ }^{24}$.

Los beneficios que dichos acuerdos generan para el sistema en términos de ahorro de recursos, y respecto del imputado al otorgarle certeza y rapidez en la resolución de su caso, no permiten sin embargo desconocer

${ }^{22}$ Por todos: Beulke W. y Satzger, H., "Der fehlgeschlagene Deal und seine Prozessualen Folgen - BGHSt 42, 191“, JuS, 1997, pp. 1072-1080, p. 1080; Braun, S., "Vorschlag für eine Absprachenregelung im Strafverfahren“, StraFo, 2001, pp. 77-83, p. 77; Eisenberg, U., Beweisrecht der StPO, München, C.H. Beck, 2017, Rn. 42 y ss.; SK-StPO-Wolter, Vor $\$ 151$, Rn 66 y ss.; Wehnert, A., "Die tatsächliche Ausgestaltung der Absprachenpraxis in staatsanwaltschaftlichen Wirtschaftsermittlungsverfahren aus anwaltlicher Sicht", StV, 2002, pp. 219-222, p. 222.

${ }^{23}$ SK-StPO-Velten, Vor $\$ \$ 257 \mathrm{~b}-257 \mathrm{c}$ ff, Rn. 10.

${ }^{24}$ Volk, K., Grundkurs StPO, 7ª Ed., München, C.H.Beck, 2010, p. 281. 
su peligrosidad: las salidas consensuadas al conflicto penal se sitúan —respecto del imputado- al límite de lo jurídicamente admisible.

Con la introducción de salidas negociadas, la presunción de inocencia ya no se desvirtúa a partir de la actividad probatoria desarrollada por el Ministerio Público en el juicio oral: su derrotabilidad se reconduce directamente a la confesión prestada por el imputado. La dictación de una sentencia absolutoria ante la imposibilidad de alcanzar por parte del tribunal el estándar probatorio exigido para condenar, es en estos casos reemplazada por sentencias dictadas, en mayor o menor grado, a partir de la confesión obtenida. Como consecuencia de ello, producto de estos acuerdos, la vigencia del principio de no autoincriminación (nemo tenetur) y de la presunción de inocencia, pilares del proceso penal moderno, quedan en entredicho $^{25}$.

Ahora bien, más allá de los cuestionamientos referidos a su incompatibilidad con ciertas garantías del imputado, las tensiones que generan los acuerdos se manifiestan intensamente con relación a su compatibilidad con ciertos principios estructurales del proceso penal alemán.

Evidente - a partir de la decimonónica estructura de la StPO — resulta la tensión entre estos acuerdos respecto del principio de legalidad, piedra angular de todo sistema (neo) inquisitivo. Los acuerdos imponen una renuncia (total o a lo menos parcial) a una potestad estatal supuestamente indisponible: la efectiva y completa averiguación y posterior persecución de los delitos cometidos. La práctica de los Absprachen supone en este sentido renunciar a la persecución total de conductas delictivas, excediendo el limitado alcance del principio de oportunidad en el sistema alemán (\$\$ 153 y ss. StPO).

La aceptación y conformidad de una confesión negociada, lleva asimismo implícito el riesgo de disipar (por vías meramente formales) las razonables dudas que el tribunal podría llegar a tener respecto de la existencia misma de un hecho constitutivo de delito y de la participación cul-

${ }^{25}$ Pese a ello, el BVerfG declaró expresamente que la regulación vigente en materia de acuerdos, no lesiona necesariamente dichos principios. Los lesionará, prosigue el tribunal, cuando en un caso concreto estos no sean por medio de un acuerdo, respetados (!): BVerfGE 133, 168 ss. 
pable del imputado en éste. Así, cuando el imputado decide aceptar un acuerdo asume un costo inevitable: la renuncia a ser declarado inocente ${ }^{26}$.

Dicha renuncia, muchas veces defendida bajo un cuestionable beneficio recíproco, implica en la práctica, liberar al tribunal de largas jornadas de rendición de prueba, aunque a un costo muchas veces demasiado elevado. La averiguación de la verdad material y la libre valoración de la prueba son, reiteramos, puestas en entredicho.

Asimismo, al aceptar el tribunal por medio de un acuerdo la imposición de una pena generalmente inferior a la que podría haberse impuesto en caso de una completa acreditación de los hechos, se vulnera la regla establecida en el $\$ 46$ del Código Penal alemán, la cual limita la imposición de una pena concreta a la culpabilidad del infractor.

A las críticas anteriores, se suma por último una lesión a principios y garantías de índole netamente procesal: la publicidad, oralidad e inmediación del juicio oral, se sustituyen por negociaciones llevadas a cabo generalmente en privado, o al menos, sin la transparencia que debiese caracterizar al procedimiento ordinario.

\section{5. ¿Acuerdos legalmente regulados, mejores acuerdos?}

La mencionada regulación legal introducida hace una década a la StPO en materia de acuerdos, más que acallar las críticas ya mencionadas, en parte las desnudó.

Paradigmática en este sentido resulta la solución propuesta por el legislador dirigida a armonizar los acuerdos, con la (necesaria) averiguación de la verdad, materializada en el nuevo $\$ 257$ c) inc. 1 StPO. Dicha disposición, señala expresamente que el principio consagrado en el $\$ 244$ inc. $2^{\circ} \mathrm{StPO}$, que impone al tribunal la obligación de averiguar de oficio la verdad valiéndose para ello de todos los medios de prueba y elementos disponibles para ello, se mantiene - respecto de los acuerdos entre imputado y juez- "intacto" 27.

\footnotetext{
${ }^{26}$ Ibidem, p. 282.

27 Por el contrario, en EE.UU. bajo el plea bargaining, la condena del acusado se funda exclusivamente sobre la base de su confesión, sin ningún otro mecanismo de atribución ni
} 
Dicha declaración, derechamente hipócrita, desconoce el peso de la realidad en pos de mantener una forzada coherencia interna, a sabiendas de la imposibilidad de dar cumplimiento a lo propuesto. Si bien, como ha sostenido el $\mathrm{BGH}^{28}$, el tribunal en estos casos no debe dictar sentencia condenatoria exclusivamente en base a la confesión, sino que debe analizar si del contenido en las actas existen o no elementos suficientes para deducir la responsabilidad penal del imputado, lo cierto es que la condena y la pena, quedan determinadas fundamentalmente a partir de dicha confesión. El viejo dogma inquisitivo confessio est regina probationum se reintroduce así al proceso alemán, paradójicamente gracias a la traducción de una institución paradigmática de un sistema pretendidamente acusatorio, como lo es el estadounidense.

\section{Respuestas consensuadas al conflicto penal: ¿Soluciones satisfactorias?}

Para justificar la introducción de soluciones negociadas al conflicto penal, no basta con constatar problemas en la aplicación reiterada de la solución ideal prevista por el legislador respecto del conflicto jurídico-penal, sino que se requiere de una justificación adicional, que redunde en algún beneficio significativo para las partes involucradas.

En principio, podría argumentarse a favor de dichos mecanismos la rebaja de la pena concreta que por medio de ellos se impone. En Alemania, por ejemplo, la esperable reducción de la pena corresponde en caso de acuerdo - estadísticamente hablando- a 1/3 de la sanción prevista en un juicio oral por conductas similares ${ }^{29}$. Ello se traduce en un innegable incentivo en aquellos casos en los cuales la posibilidad de absolución, a la luz de la evidencia recopilada, resulte especialmente baja.

Ahora bien, más allá de las cifras: ¿resultan estas salidas negociadas al conflicto penal, realmente satisfactorias para los involucrados? Esbozar 
una única respuesta resulta imposible. Las luces y sombras que genera su aplicación, muchas de ellas ya descritas, impiden una valoración binaria.

Para un sector de la doctrina alemana, estas salidas corresponden a herramientas que fomentan la democratización del proceso penal ${ }^{30}$. Los intervinientes estarían libremente en condiciones de decidir respecto de su futuro procesal, flexibilizando el otrora rígido sistema de enjuiciamiento, en pos de una solución consensuada y por ello, más eficiente.

Si bien intuitivamente una negociación podría resultar a priori preferible ante una solución héterocompositiva impuesta por un juez (de resultado incierto), muchas veces las expectativas de los intervinientes, respecto del resultado de los acuerdos, se ven finalmente frustradas. En Alemania, estadísticas del año 2007 demuestran que el 30,9\% de los fiscales reconocieron que las penas finalmente impuestas al acusado por medio de un Absprache, resultaron demasiado leves respecto de la conducta imputada. Por el contrario, el 30,3\% de los defensores estimó que la sanción aplicada por intermedio de un acuerdo resultaba desproporcionadamente alta con relación a los hechos acaecidos ${ }^{31}$.

La tensión reflejada en las (muchas veces frustradas) expectativas de los intervinientes, encierra asimismo una pregunta sustantiva: ¿Puede considerarse el "consenso" respecto de la imposición de una pena como un indicador a favor de la "justicia" de la decisión? A la luz de lo expuesto, difícilmente. Como señalaba un autor, los acuerdos representan un verdadero "embrutecimiento del procedimiento" ${ }^{32}$, imponiendo soluciones espurias, alejadas muchas veces de la realidad material, que como se mencionó anteriormente, lesionan principios fundamentales del ordenamiento.

\footnotetext{
${ }^{30}$ Lüderssen, K., "Die Verständigung Im Strafprozeß - Überlebensstrate- gie oder Paradigmawechsel“, StV, 1990, p. 415-420, p. 415 y ss.

31 Altenhain, K., Dietmeier, F. y May, M., Praxis der Absprachen, Baden-Baden, Nomos, 2013, passim.

32 Dencker, F. y Hamm, R., Der Vergleich im Strafprozess, Neuwied, Hermann Luchterhand Verlag, 1988, p. 57.
} 


\section{El procedimiento abreviado en el sistema procesal penal chileno}

En los 100 años de vigencia del sistema inquisitivo consagrado en el antiguo Código de Procedimiento Penal chileno (1906), el juez del crimen, consecuente y a la vez precario representante del inquisidor, detentaba las funciones de investigación de conductas criminales, formulación de la acusación ${ }^{33}$ y fallo.

La inversión de recursos por parte de defensas (muchas veces precarias e incluso iletradas), dirigida a demostrar la inocencia del imputado chocaba dramáticamente frente a la quimera de la absolución, verdadero acto de esquizofrenia de un juez que a último minuto decidía arrepentirse de su propia imputación.

Ahora bien, más allá de los vicios de parcialidad que indiscutidamente pueden atribuírsele a un persecutor que finalmente acusará y resolverá el caso, el antiguo sistema procesal chileno demostró ser enormemente ineficiente. El procedimiento ordinario por crimen o simple delito de acción penal pública representaba formalmente el único mecanismo reconocido por el legislador para sancionar conductas delictivas. Los sobrecargados jueces del crimen carecían igualmente de los recursos necesarios y sobre todo de una estructura procedimental idónea para juzgar adecuadamente las distintas conductas constitutivas de delitos.

El fracaso constatable del sistema se evidenciaba en investigaciones eternas, múltiples sobreseimientos temporales (a la espera de recopilar mejores antecedentes para reabrir una y otra vez investigaciones destinadas al fracaso), en la pérdida de relevancia práctica de ciertas fases del procedimiento $^{34}$ y sobre todo en las bajas cifras de éxito alcanzadas.

${ }^{33}$ Ello a partir de la reforma introducida por medio del DFL N ${ }^{\circ} 426$ del 3 de marzo de 1927 que suprime los cargos de promotores fiscales que constituían el Ministerio Público en la primera instancia. Esto significó uno de los mayores cambios que se pudieron hacer a dicho Código, pues se suprime uno de los sujetos procesales radicando sus facultades al juez, quien entonces pasaría a ser un órgano acusador.

34 En este sentido, el plenario, la etapa "propiamente de juicio" originalmente consagrada, en la cual la defensa podía controvertir la prueba de cargo y presentar prueba de descargo,

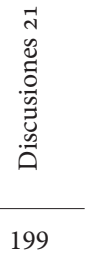


El extremo formalismo y rigidez del sistema, impedía contar con soluciones diferenciadas según la gravedad y naturaleza del delito investigado, y además, privaba de toda relevancia a la voluntad del imputado. Si la verdad material debía ser alcanzada en todos los casos y a cualquier costo, la confesión del imputado sólo se entendía bajo el dogma inquisitivo de mecanismo para la averiguación de la verdad material, carente de significado procedimental, generando (a lo sumo) una atenuante de responsabilidad penal.

Dicho modelo dio paso, a comienzos de este siglo, a un nuevo cuerpo legal, el Código Procesal Penal (CPP), el cual a diferencia de su criticado predecesor, consagró diversos mecanismos consensuados de resolución de conflictos penales ${ }^{35}$.

El sistema procesal penal actualmente vigente asume explícitamente la imposibilidad de reconocer un solo mecanismo de resolución de conflictos, aplicable a todos los hechos constitutivos de delito. La utopía de la sentencia definitiva generada a partir de un juicio oral, público y contradictorio, como ideal irrenunciable, ha cedido terreno frente a instituciones y realidades antes desconocidas en Chile.

De este modo, el juicio oral (si bien reconocido por el legislador como una garantía a favor del imputado ${ }^{36}$ ) se reserva en la práctica, exclusivamente para el juzgamiento de aquellos delitos de mayor gravedad. Las conductas menos lesivas son resueltas por medio de salidas alternativas, por aplicación del (aún limitado) principio de oportunidad o bien, en sede contenciosa, por aplicación de los procedimientos abreviado, simplificado o - en el caso de las faltas- monitorio.

En los que a esto último respecta, el procedimiento abreviado constituye una de las más significativas innovaciones introducidas por al legislador chileno en el año 2000. Regulado en los arts. 406 a 415 CPP, dicho procedimiento se estructura en base a la aceptación por parte del acusado

derivó en una mera reiteración de los antecedentes probatorios anteriormente recopilados por el juez del crimen y sus subalternos durante el sumario.

35 Por ejemplo: los acuerdos reparatorios (arts. 241 y ss. CPP); la suspensión condicional del procedimiento (arts. 237 y ss. CPP) y el reconocimiento de responsabilidad en el procedimiento simplificado (art. $395 \mathrm{CPP}$ ). 
de los hechos por los cuales se le acusa y de los antecedentes que fundamentan dicha imputación.

En este sentido, el procedimiento abreviado chileno ha sido concebido como un procedimiento contradictorio, en el cual la manifestación de voluntad del imputado, objeto y requisito ineludible de aplicación del procedimiento abreviado, consiste - a diferencia del plea bargaining - no en una aceptación de responsabilidad penal, sino en una aceptación de los hechos materia de la acusación formulada por el ente persecutor, y de los antecedentes de la investigación que la fundaren (art. 406 inc. $2^{\circ} \mathrm{CPP}$ ). Consistente con lo anterior, y tal como sucede en Alemania ${ }^{37}$, el art. 412 inc. $2^{\circ}$ $\mathrm{CPP}$ advierte que la sentencia condenatoria no podrá emitirse exclusivamente sobre la base de la aceptación de los hechos por parte del imputado. Para materializar dicho principio, se contempla la existencia de una audiencia de procedimiento abreviado (art. $411 \mathrm{CPP}$ ), en la cual los intervinientes debatirán respecto de las consecuencias jurídicas de los hechos aceptados, y de los antecedentes probatorios que las fundan. La posibilidad de dictar sentencia absolutoria corresponde, en honor al referido carácter contradictorio del procedimiento, a una hipótesis jurídicamente posible. En este sentido, la adopción del plea bargaining en el derecho chileno, corresponde - como afirma Langer ${ }^{38}$ respecto de los sistemas latinoamericanos- a una manifestación diferente al modelo estadounidense.

En la práctica, sin embargo, el procedimiento abreviado chileno se aleja considerablemente del ideal propuesto por el legislador, estructurándose en torno a una verdadera parodia de juicio, dirigida a la (ineludible) imposición de una sentencia condenatoria. La mínima actividad probatoria que dicho procedimiento - pese a la conformidad del acusado- exige (tal como sucede con la ya analizada regla contenida en el $\$ 257 \mathrm{c}$ inc. $1^{\circ}$ StPO) de acuerdo con el mencionado art. 412 inc. $2^{\circ} \mathrm{CPP}$, se traduce en una simple repetición mecánica de los antecedentes de la investigación recopilados, secundada por el silencio cómplice de la defensa. Precisamente, la venia del Ministerio Público para acceder a esta solución se sustentará muchas veces en la pasividad pactada de la defensa, la cual se comprome-

${ }^{37}$ Langer, M., op. cit., sección 7.

${ }^{38}$ Ibidem, sección 1. 
terá a no contradecir los antecedentes esgrimidos en la audiencia por el ente persecutor. Lo anterior deriva en una práctica donde el centro de la adjudicación se desplaza desde el tribunal, hacia la imputación del fiscal ${ }^{39}$.

La regulación original del procedimiento abreviado en Chile consideró especialmente las críticas dirigidas al plea bargaining, el cual favorecería la práctica masiva de la renuncia al juicio y sus garantías a cambio de reducciones importantes de la pena impuesta, motivadas por una negociación previa con el fiscal ${ }^{40}$. Para lograr dichos fines, el Código del año 2000 se encargó de limitar su procedencia a imputaciones de mediana gravedad, sancionadas con una pena no superior a los 5 años de privación de libertad ${ }^{41}$.

Sin embargo, la reforma legal introducida recientemente por medio de la ley $20.931^{42}$, ha desdibujado el panorama descrito. Por medio de dicha ley, se amplió el ámbito de aplicación del procedimiento abreviado (art. 406 $\mathrm{CPP}$ ), resultando en la actualidad procedente respecto de ciertos delitos contra la propiedad (hurto y distintas formas de robo descritas en la legislación sustantiva) sancionados con penas de hasta 10 años de privación de libertad ${ }^{43}$. Como consecuencia de dicha reforma, resulta actualmente posible juzgar por medio de este procedimiento conductas cuya sanción derivará inevitablemente en la aplicación de penas efectivas de privación total de libertad, ratificando la validez de las críticas que cuestionan la voluntariedad de la conformidad del imputado frente a la amenaza de una sanción aún más elevada.

39 Al respecto: Riego, C., "El procedimiento abreviado en la ley 20.931", Política Criminal, 12 (24), 2017, pp. 1085-1105, p. 1099 y ss.

40 Ibidem, p. 1086.

${ }^{41}$ La relevancia de dicha pena coincide con el límite máximo de pena susceptible de ser reconducido a una pena sustitutiva a las penas privativas o restrictivas de libertad, de acuerdo a la ley 18.216 (ley que establece penas sustitutivas a las penas privativas o restrictivas de libertad).

42 Publicada el 5 de Julio de 2016.

${ }^{43}$ Estadísticamente, la inclusión de este tipo de conductas dentro del ámbito de aplicación del procedimiento abreviado resulta relevante pues, de acuerdo a estadísticas del año 2005, los delitos contra la propiedad constituyeron entonces un $37,12 \%$ del total de los ingresos al sistema procesal penal. Riego, C., op. cit., p. 1095. 


\section{Soluciones consensuadas como reacción a problemas estructurales del proceso penal: el costo de la ineficiencia}

Lo señalado previamente permite demostrar, a lo menos, que las soluciones consensuadas al conflicto penal no se encuentran libres de reproche. Tras la (pretendida) negociación y posterior acuerdo de voluntades, se esconden presiones, precariedad, desinformación y desproporción.

La masificación de las salidas negociadas en el proceso penal (y en consecuencia de los referidos problemas que ellas conllevan), no tienen necesariamente su origen en la regulación legal, ni tampoco en el acuerdo o solución acordada en sí, sino que pueden entenderse como respuestas casi espontáneas y esperables frente a una regulación en gran medida insuficiente.

En este sentido, la inclusión y estandarización de estas salidas negociadas en distintos sistemas legales, puede obedecer contra intuitivamente, a una reacción a lo que comúnmente se erige como su mayor estandarte: las reformas al proceso penal, generadas a partir de la presión por mayores garantías a favor del imputado, condujeron finalmente a la desnaturalización del juicio oral tornándolo en impracticable como procedimiento de rutina para la resolución de casos penales ${ }^{44}$. El juicio oral - tanto en EE.UU., como en Alemania y Chile - se ha trasformado progresivamente en una salida anómala al conflicto penal, absorbiendo el sistema el costo de una sobrerregulación del mismo que redunda, casi inconscientemente, en su desuso. El juicio oral constituye actualmente tanto un privilegio, como una instancia cargada de incertidumbre, a la cual — por razones presupuestarias y materiales - no todos pueden o desean acceder. En efecto, como descarnadamente sostuvo la Corte Suprema estadounidense en Santobello v. New York: “(...) si todas las acusaciones hubieren de ser llevadas al juicio oral, a fin de lograr una completa actividad procesal, los Estados y el propio Gobierno Federal necesitarían aumentar considerablemente el número de jueces y el número de tribunales" ${ }^{45}$.

${ }^{44}$ Langbein, J., op. cit., p. 13.

45 Santobello v. New York 404 U.S. 257, 260 (1971). 
De este modo, la existencia de salidas consensuadas al conflicto jurídico penal, eficientes en orden a lograr una masiva persecución de conductas constitutivas de delitos, tal como un tratamiento paliativo sólo combate los síntomas de una enfermedad, más no sus causas, impiden muchas veces detenerse en los problemas estructurales que aquejan al proceso penal.

El diagnóstico anterior no es sólo sintomático del sistema estadounidense, sino que trasciende a los sistemas chileno y alemán.

En este último, la extensión total y programación del juicio dependerá fundamentalmente de la agenda del tribunal. La realización habitual del juicio por medio de sucesivas audiencias discontinuas, atenta desde luego contra la inmediación, diluyendo la frágil memoria de los sentenciadores ${ }^{46}$. En este sentido y como sostenía Beccaria, el proceso penal "debe acabarse en el más breve tiempo posible" ${ }^{47}$. Precisamente, la demora en la resolución del asunto es uno de los motivos que fomentan la búsqueda de soluciones consensuadas al conflicto penal por parte de los actores del mismo.

En el caso chileno, el juicio oral, eficiente para el juzgamiento de hechos de escasa o mediana complejidad, tiende a mostrarse insuficiente frente a casos difíciles.

Así, pese a regular el CPP expresamente (art. 282) que el juicio oral se desarrollará en forma continua y podrá prolongarse en sesiones sucesivas, lo cierto es que el sistema vigente no se encuentra diseñado para resolver eficientemente por esta vía, casos complejos referidos fundamentalmente a la criminalidad económica.

Exigir por meses, día tras días, la presencia interrumpida de abogados defensores, fiscales, testigos, peritos y jueces, constituye en muchos casos un costo demasiado alto para juzgar conductas que -independiente del significado social a ellas atribuido - finalmente son levemente sancionadas por la legislación sustantiva chilena. El fantasma de un extenso juicio oral es entonces, justa o injustamente percibido como innecesario, frente a una

\footnotetext{
${ }^{46}$ Una visión crítica de la excesiva duración del proceso penal alemán, así como de las consecuencias jurídicas que esto ocasiona se encuentra en: Scheffler, U., Die überlange Dauer von Strafverfahren Materiellrechtliche und prozessuale Rechtsfolgen, Berlin, Duncker \& Humblot, 1991, passim.

47 Beccaria, C., De los delitos y las penas, México-DF, Fondo de Cultura Económica, 2000, p. 258.
} 
conducta que - desde un comienzo - todos saben no terminará, por las bajas penas asociadas y la consecuente aplicación de beneficios legales, con el sentenciado efectivamente privado de libertad.

Ahora bien, independiente de las particularidades del caso concreto, la regulación misma del juicio oral se muestra, al menos en el caso chileno, ineficiente.

Sólo a modo de ejemplo, a la innecesaria regla que ordena al comienzo del juicio oral dar lectura íntegra a la o las acusaciones que serán objeto del juicio (art. 325 inc. $3^{\circ} \mathrm{CPP}$ ), se suma la regulación imperfecta de la prueba pericial, que exige que los peritos en el juicio oral expongan al comienzo de su presentación el contenido de su informe pericial y las conclusiones del mismo. Dichas largas alocuciones, muchas veces irrelevantes, sólo postergan los interrogatorios de los intervinientes, momento en el cual el testimonio experto es realmente contrastado y sometido a examen por parte de los intervinientes. Similares problemas se observan respecto de la incorporación al juicio de la prueba documental (art. $333 \mathrm{CPP}$ ). A las interminables lecturas de documentos, se suman declaraciones de testigos destinadas exclusivamente a reconocer o contextualizar dichos elementos probatorios.

Los defectos sin embargo no se reducen al juicio oral. Ya en la etapa intermedia, el sistema chileno adolece de serias deficiencias respecto - por ejemplo- de la regulación de ciertos medios de prueba, especialmente de la pericial. Actualmente, dado el limitado control de admisibilidad efectuado por los jueces, prácticamente cualquier sujeto autodenominado perito, independiente de su idoneidad y pertinencia, podrá ser admitido como medio de prueba en el juicio oral ${ }^{48}$.

De este modo, resulta pertinente traer a colación una de las tesis centrales de Langer: la obtención del consentimiento del imputado mediante negociaciones o la oferta de beneficios, puede derivar en que los procesos penales regulares sean innecesarios, o al menos puede brindar una justificación para simplificarlos o directamente evitarlos ${ }^{49}$. En el sistema

\footnotetext{
48 Sobre la necesidad de establecer mayores estándares a la admisibilidad de la prueba pericial: Duce, M., La prueba pericial, Buenos Aires, Editores Didot, 2015, p. 55 y ss.; Vázquez, C., De la prueba científica a la prueba pericial, Madrid, Marcial Pons, 2015, p. 156 y ss.

${ }^{49}$ Langer M., op. cit., sección 6.
} 
chileno, la introducción de mecanismos de negociación consensual efectivamente ha contribuido a flexibilizar sistemas no diseñados o al menos no completamente idóneos para hacer frente al fenómeno de la criminalidad compleja del siglo XXI.

En efecto, las soluciones negociadas al proceso penal han surgido con independencia del sistema - acusatorio, inquisitivo o mixto - del que se trate, pues corresponden a una reacción prácticamente inevitable del sistema, en su búsqueda por optimizar el uso de recursos frente a una política criminal cada vez más compleja y demandante. Las salidas negociadas se erigen de este modo como soluciones apenas aceptables que, si bien resignan los aspectos esenciales del procedimiento ordinario, permiten evitar que muchas conductas criminales queden finalmente en la impunidad.

Precisamente a partir de lo anteriormente señalado, cabe matizar lo sostenido por Langer ${ }^{50}$ al describir el plea bargaining como una de las prácticas más incompatibles con el sistema inquisitivo y el modelo de la investigación oficial. Como señalábamos anteriormente, si bien históricamente el plea bargaining ha sido percibido como un elemento central y paradigmático del sistema procesal penal estadounidense, de corte acusatorio, ello parece a estas alturas ser algo casi anecdótico. Las salidas consensuadas al conflicto penal resultan hoy en día prácticamente inevitables para cualquier sistema procesal penal que tenga alguna pretensión de eficiencia que satisfacer; estas salidas se adoptarán - ya sea formal o informalmentepor más que el sistema originalmente concebido no las haya consagrado originalmente o resulten prima facie incompatibles con éste.

Como expuso certeramente el autor del artículo objeto de este comentario, cualquier intento de modificar una estructura de interpretación y sentido, por lo general va a producir una reacción de protesta por parte de los jueces contra la pérdida de facultades a través de una nueva estructura procesal de sentido ${ }^{51}$. La conclusión anterior no debe entenderse como un intento

50 Langer M., op. cit., sección 6.

51 Langer M., op. cit., sección 2. Un claro ejemplo para ilustrar dicha situación se encuentra en la oposición manifestada por el Pleno de la Corte Suprema chilena en relación a ciertos aspectos de la Reforma Procesal Civil chilena, actualmente en tramitación parlamentaria, y que busca - por ejemplo - limitar algunas potestades del máximo tribunal en materia de recursos. Al respecto, se critica por parte del máximo tribunal especialmente la regulación 
de resignación. Por el contrario, solucionar los problemas expuestos en esta sección, si bien no constituye una tarea sencilla, resulta necesario. De este modo, la referida protesta - por cierto esperable - puede con el tiempo ser acallada por medio de reformas legales que a la larga se demuestren exitosas.

\section{Recapitulación: La incidencia de los acuerdos en los sistemas jurídicos analizados}

La conformidad del acusado, ya sea respecto de los hechos de la acusación, o en relación con su culpabilidad, independiente de la forma específica que ella adopte, y de los límites que un determinado sistema pueda imponerle al momento de ser traducida a éste, provee innegables ventajas para el sistema que lo adopta. Los ya mencionados beneficios enunciados por la Corte Suprema de los Estados Unidos en Santobello v. New York (entre otros: rapidez en la resolución del asunto, limitación de los efectos de la prisión preventiva y mejoras en las perspectivas de rehabilitación), constituyen sin lugar a dudas ventajas extrapolables a los sistemas comparados, que su introducción ha generado. Para ello, reiteramos, no es necesario trasplantar íntegramente el procedimiento estadounidense a un sistema foráneo, ni siquiera sólo una parte de éste, sino simplemente incorporar una institución ajena, en pos de obtener (al menos alguno de) los beneficios que ésta genera.

Efectivamente, como correctamente se desprende del artículo de Langer, tanto la modificación legal introducida a la StPO hace 10 años, y que consagró formalmente los Absprachen en dicho ordenamiento, como el reconocimiento del procedimiento abreviado en Chile, no han "americanizado" mayormente el proceso penal alemán ni el chileno. El modelo

del nuevo recurso extraordinario, reemplazante de la actual casación, reprochando la explicita limitación de las atribuciones que el máximo tribunal considera "que por esencia le son propias". La Corte Suprema a este respecto, se inclinó en su informe lisa y llanamente por mantener el actual recurso de casación —en sus palabras- "como está". Oficio N ${ }^{\circ} 24-2013$, Informe proyecto ley 7-2012, Antecedente: Boletín $N^{\circ}$ 8197-07. Santiago, 31 de enero de 2013. Disponible en: https://www.camara.cl/pdf.aspx?prmID=9847\%20\&prmTIPO=TEXTOSESION. 
tradicional inquisitivo reformado del proceso penal alemán y el modelo mixto chileno, simplemente han introducido un elemento de "descompresión" de los mismos que, si bien resulta en mayor o menor grado ajenos a su estructura, no ha incidido más allá de los (aún) acotados márgenes de su aplicación.

Para corroborar la conclusión anterior, basta con mencionar la ya criticada subsistencia en el derecho alemán, de aquella regla que impone una obligación para el tribunal de averiguar de oficio la verdad, aun en caso de alcanzar las partes un acuerdo. Ella constituye hoy en día un elemento meramente retórico, dirigido a mantener al menos formalmente una estructura interna coherente frente a una realidad distinta. Lo mismo sucede en el caso chileno; si bien la mencionada absolución del imputado en el procedimiento abreviado constituye una posibilidad cierta, de acuerdo con la estructura procedimental ya descrita, el rol pasivo de la defensa, previamente negociado con el fiscal, termina por reducirla a un plano meramente simbólico. La sentencia condenatoria, si bien no formalmente, en la práctica se erige como la consumación de una solicitud del Ministerio Público.

De este modo, podemos sostener que los resguardos buscados por el legislador, a efectos de mantener vigentes ciertos principios estructurales del proceso penal, a pesar del reconocimiento formal de acuerdos tan ajenos a la regulación original, se muestran muchas veces en la práctica como obstáculos burocráticos que no han impedido a los actores arribar a soluciones rápidas y eficientes. La "desformalizada y eficientista" realidad se impone frente al esfuerzo de mantener consistencia a nivel legislativo.

En este sentido, resulta revelador señalar que mediante una encuesta realizada el año 2011 entre diversos jueces alemanes ${ }^{52}$ - ya vigente la reforma legal que consagró expresamente los acuerdos en la StPO- más de la mitad de ellos reconoció que su tribunal conduce acuerdos que se alejan en mayor o menor medida de la legislación vigente. Incluso, las cifras indican que cerca del $60 \%$ del total de los Absprachen realizados ese año entre los consultados fueron realizados al margen de la regulación vigente, fundamentalmente del $\$ 257$ c) StPO, disposición que, al establecer nume- 
rosos requisitos formales para el desarrollo y perfeccionamiento de los acuerdos, es percibida por los intervinientes como "un exceso formalista".

El fenómeno descrito muestra más bien una creciente fragmentación del procedimiento penal ${ }^{53}$, entendida como un proceso de diferenciación interna estructurado en base al pragmatismo, que ha generado casi forzosamente salidas antes vetadas como respuesta a los crecientes problemas que enfrenta la persecución y posterior juzgamiento de conductas criminales.

\section{0. ¿Traducciones o trasplantes?}

Finalmente, el análisis propuesto en esta entrega permite constatar la validez de una de las tesis fundamentales enunciadas por Langer ya al comienzo de su trabajo ${ }^{54}$ : si bien la influencia del plea bargaining estadounidense en los sistemas comparados es innegable, a pesar de ello, la “importación” del plea bargaining en las jurisdicciones aquí analizadas no reproduce el modelo estadounidense de proceso penal.

Lo anterior, permite concluir que la incorporación de soluciones negociadas al conflicto penal en los sistemas alemán y chileno, independiente de los motivos que llevaron a ello, presenta diferencias sustanciales respecto del plea bargaining estadounidense, incorporando elementos característicos del sistema en el cual éstas se introducen. Ello permite a su vez corroborar la tesis central de Langer ${ }^{55}$, en cuanto descarta la validez de la metáfora del trasplante legal, como principal herramienta dirigida a analizar la importación de prácticas legales foráneas ${ }^{56}$. Por el contrario, la flexibilidad del concepto de traducción (ya esbozada por Langer ${ }^{57}$ ), permite entender las características particulares generadas en cada sistema, como consecuencia de la interacción con las prácticas judiciales penales preexistentes, en desmedro de la rigidez que plantea la idea de trasplante ${ }^{58}$.

\footnotetext{
53 La idea, propuesta por Langer M., se encuentra en op. cit., sección 8 y 9.

54 Langer, M., op. cit., sección 1.

55 Langer, M., op. cit., sección 1.

56 Langer, M., op. cit., sección 7.

57 Langer, M., op. cit., sección 7.

58 Langer, M., op. cit., sección 5.
} 
De este modo, las características propias de la regulación legal y la práctica en los sistemas aquí analizados, impide concluir que se trate en estos casos - como acertadamente sostiene el autor- de un mero "cortar y pegar", presentando estos elementos idiosincráticos, no reconocidos - $\mathrm{O}$ derechamente incompatibles - con el sistema estadounidense.

\section{A modo de conclusión: la mirada optimista desde una experiencia exitosa}

La experiencia estadounidense, chilena y alemana ha demostrado cómo las soluciones consensuadas no sólo logran salir de la clandestinidad que en sus orígenes las caracterizaba, sino que logran finalmente imponerse como mecanismo recurrente de resolución de conflictos penales. Lo anterior no implica, sin embargo, que el procedimiento ordinario, paradigma de los principios y garantías que orientan el proceso penal moderno, esté condenado a la desaparición.

En este sentido y a modo ejemplar, la experiencia en torno a la supresión y posterior limitación del plea bargaining en el Estado de Alaska, entre los años 1975 y 1990 puede dar algunas luces respecto del futuro. Durante dicho lapso de tiempo, la experiencia políticamente impulsada, dirigida a la supresión de los acuerdos tanto de cargos como de sentencia, tuvo un efecto muy distinto del colapso local de la justicia penal por muchos previsto y esperado. La eliminación y posterior reducción del ámbito de aplicación de dicho mecanismo negociado de solución de conflictos penales, permitió mejorar el tiempo de resolución de casos, propiciando igualmente la materialización de sendas reformas legislativas que incidieron en una mayor eficiencia del sistema y una progresiva uniformidad en la aplicación de penas respecto de hechos similares ${ }^{59}$.

Así, más que potenciar y reforzar legislativamente el uso de soluciones consensuadas, la pérdida de relevancia práctica de ciertas instituciones 
paradigmáticas del proceso penal debiese motivar un diagnóstico que permita analizar y resolver los problemas de fondo subyacentes a éste.

El necesario perfeccionamiento y actualización de los procedimientos contradictorios, generará su reposicionamiento como mecanismos idóneos de resolución de conflictos penales, utilizables — sin reparos - frente a cualquier imputación. Lo anterior permitirá controlar de mejor manera la práctica de soluciones negociadas, limitando su aplicación a aquellos casos en los cuales se generen reales beneficios para los involucrados.

\section{Bibliografía}

Altenhain, K., Dietmeier, F. y May, M., Praxis der Absprachen, BadenBaden, Nomos, 2013.

Beccaria, C., De los delitos y las penas, México-DF, Fondo de Cultura Económica, 2000.

Beling, E. y Bennecke, H., Lehrbuch des Deutschen Reichs-Strafprozessrecht, Breslau, Schletter'sche Buchhandlung, 1900.

Beulke W., Strafprozessrecht, 11. Ed., Heildelberg y otros, C.F. Müller, 2010. Beulke W., Satzger, H., "Der fehlgeschlagene Deal und seine Prozessualen Folgen - BGHSt 42, 191”, JuS, 1997, pp. 1072-1080.

Braun, S., "Vorschlag für eine Absprachenregelung im Strafverfahren", StraFo, 2001, pp. 77-83.

Correa, C., "Más allá de la regla de exclusión: prohibiciones probatorias en el Derecho chileno - con especial referencia al Derecho alemán-”, Política Criminal, 13, 25, 2018, pp. 144-174.

Correa C. y Reyes, M., El procedimiento abreviado y la justicia criminal negociada - Derecho chileno y comparado-, Santiago, Ed. Jurídica, 2012.

Damaska, M., El derecho probatorio a la deriva, Madrid, Marcial Pons, 2015.

Dencker, F. y Hamm, R., Der Vergleich im Strafprozess, Neuwied, Hermann Luchterhand Verlag, 1988.

Duce, M., La prueba pericial, Buenos Aires, Editores Didot, 2015. 
Eisenberg, U., Beweisrecht der StPO, München, C.H. Beck, 2017.

Kempf, E., "Gesetzliche Regelung von Absprachen im Strafverfahren? Oder: Soll informelles formalisiert werden?", StV, 2009, pp. 269-276.

Langbein, J., “Tortura y plea bargaining”, en Maier, J. y Bovino, A. (coord.), El procedimiento abreviado, Buenos Aires, Editores del Puerto, 2001, pp. 3-29.

Langer, M., "From Legal Transplants to Legal Translations: The Globalization of Plea Bargaining and the Americanization Thesis in Criminal Procedure", Harvard International Law Journal, 45, 1, 2004, pp. 1-64.

Lüderssen, K., “Die Verständigung Im Strafprozeß - Überlebensstrate- gie oder Paradigmawechsel“, StV, 1990, pp. 415-420.

Riego, C., "El procedimiento abreviado en la ley 20.931", Política Criminal, 12, 24, 2017, pp. 1085-1105.

Roxin, C., "La posición jurídica de la fiscalía ayer y hoy", en Guerrero, Ó (traductor), Pasado presente y futuro del Derecho Procesal Penal, Buenos Aires y Santa Fe, Rubinzal Culzoni Editores, 2007, pp. 9-38.

Scheffler, U., Die überlange Dauer von Strafverfahren Materiellrechtliche und prozessuale Rechtsfolgen, Berlin, Duncker \& Humblot, 1991.

Varios autores, "Alaska's Plea Bargaining Ban Re-evaluated - Alaska Judicial Council”, 1991. Disponible en: www.ajc.state.ak.us/reports/plea91Exec. pdf

Varios Autores, SK-StPO: Systematischer Kommentar zur Strafprozessordnung. Mit GVG und EMRK, Editado por: Wolter. Tomos III: $\$ \$ 137$ - 197 y V: $\$ \$ 246 a-295$ StPO, 5. Ed., Köln, Heymanns, 2016. Citado como: SK-StPO-Autor de la sección.

Vázquez, C., De la prueba científica a la prueba pericial, Madrid, Marcial Pons, 2015.

Volk, K., Grundkurs StPO, 7ª Ed., München, C.H.Beck, 2010.

Wehnert, A., "Die tatsächliche Ausgestaltung der Absprachenpraxis in staatsanwaltschaftlichen Wirtschaftsermittlungsverfahren aus anwaltlicher Sicht“, StV, 2002, pp. 219-222. 